\title{
Forecasting UK Industrial Production over the Business Cycle
}

\author{
Paul W. Simpson* $\quad$ Denise R. Osborn $\dagger \quad$ Marianne Sensier $\dagger$ \\ *Department for Education and Employment, Sheffield \\ $†$ Centre for Growth and Business Cycle Research \\ School of Economic Studies \\ University of Manchester, Manchester, M13 9PL, UK \\ web address: http://www.ses.man.ac.uk/cgbcr/ \\ e-mail: Marianne.Sensier@man.ac.uk. \\ Phone: 0161275 4866, Fax: 01612754812 \\ $25^{\text {th }}$ January 2000
}

\begin{abstract}
This paper examines the information available through leading indicators for modelling and forecasting the UK quarterly index of production. Both linear and non-linear specifications are examined, with the latter being of the Markov-switching type as used in many recent business cycle applications. The Markov-switching models perform relatively poorly in forecasting the 1990s production recession, but a three indicator linear specification does well. The leading indicator variables in this latter model include a short-term interest rate, the stock market dividend yield and the optimism balance from the quarterly CBI survey.
\end{abstract}

JEL classification: C22, C32, E27, E32, E44.

Keywords: Financial variables, business cycles, leading indicators, Markov-switching models, forecast performance. 


\section{INTRODUCTION}

This paper examines the extent to which leading indicators improve forecast accuracy for quarterly real UK industrial production over the business cycle. In particular, we focus on forecasts for the 1990s. This period is of particular interest because, after a period of substantial expansion during the latter half of the 1980s, the UK economy saw the occurrence of a deep recession which, although later attributed to endogenous factors, was widely unpredicted at the time (Dow, 1998, p321). Thus, we are interested in whether there were signs that UK industrial production would go into recession and whether the length and depth of that recession were signalled by the information then available. Although we have the benefit of hindsight in carrying out such an analysis, it is nevertheless the case that lessons need to be learnt from such episodes if they are to be avoided in the future.

Business cycles are a key feature of our analysis. It has often been observed that the business cycle is asymmetric in the sense the economy behaves differently during expansions and recessions. A wide variety of linear and non-linear time-series techniques have been employed to model business cycle features, but a major theoretical limitation of linear business cycle models is that they are generally incompatible with cyclical asymmetries. In consequence, much recent interest has focused on non-linear business cycle models. Perhaps surprisingly, however, Hess and Iwata (1997) produce evidence that (in a univariate context) non-linear models are in practice no better at reproducing the business cycle features of US output than a simple linear time series model. Further, the forecasting record of non-linear models for macroeconomic variables is mixed (Ramsey, 1996). Therefore, in the current paper, we adopt both linear and non-linear approaches to evaluate the forecasting role of leading indicator variables.

Several non-linear business cycle methods have been employed in the literature to capture observed business cycle asymmetries. These include threshold models (Tiao and Tsay, 1994), smooth transition autoregressive models (Teräsvirta and Anderson, 1992, Osborn and Öcal, 1998) and Markov-switching regime models (Hamilton, 1989, Filardo, 1994). Of these, we adopt the Markov-switching approach because it can focus on the phase of the business cycle. Indeed, in applying a two regime Markov-switching model to post-war US quarterly real gross national product growth, Hamilton obtained regimes which correspond closely with the US business cycle expansion and recession phases as dated by the widely-respected National Bureau of Economic Research.

Despite the recent interest in modelling the business cycle, the vast bulk of the time series literature on this topic uses univariate models. However, in order to forecast business cycle movements, it may be anticipated that leading economic indicators should convey 
useful information about output, whether gross domestic product or industrial production. Filardo (1994) developed the Markov-switching model to allow leading indicators to play a role through time-varying transition probabilities (TVTP), where the probability of a change in regime varies with movements in leading indicator variables. In applying his TVTP Markov-switching model to the monthly US index of production (IOP) using various leading indicator series, he found evidence in support of business cycle asymmetries and the TVTP specification. Nevertheless, he did not attempt to evaluate the role of the leading indicators through a forecast evaluation exercise.

As noted above, our interest is in evaluating the role of leading indicators for forecasting. In common with most leading applications, including the leading indicator system for the UK formerly produced by Office for National Statistics (Moore, 1993), the information context of the indicators is evaluated in a reduced form context which is free from any specific model specification suggested by economic theory. Nevertheless, we consider both linear and non-linear specifications, and also univariate models as standards of comparison for the models employing leading indicator variables. In our complementary paper, Simpson, Osborn and Sensier (1999), we focus on UK gross domestic product (GDP) and find evidence that the Markov-switching models and the use of leading indicators (especially interest rates) deliver improved forecast accuracy. Here we examine forecasts of industrial production. This variable exhibits more marked post-war cyclical movements than GDP, because it excludes the service sector which experienced almost unbroken post-war growth in the UK until the end of the 1980s. In common with our GDP paper, the leading indicators we consider are housing starts, the Confederation of British Industry (CBI) optimism balance and a number of financial variables.

The structure of the paper is as follows: the Methodology Section discusses the empirical models, including the procedures used to derive the particular specifications adopted. The Data Section describes the data employed in the analysis. Substantive results are presented in the following two sections, the first (Selected Models) discusses the estimation results for both the linear and Markov-switching models, while the second (Forecast Results) compares their forecasting performance. Finally, some conclusions are presented. 


\section{METHODOLOGY}

\section{Linear Models: specification, estimation and diagnostic tests}

A linear autoregressive (AR) model for the growth rate of $\operatorname{IOP}\left(y_{t}\right)$ is:

$$
y_{t}=\alpha+\phi(L) y_{t}+e_{t}
$$

where $\alpha$ is the intercept, $\phi(L)=\phi_{1} L^{1}+\phi_{2} L^{2}+\ldots+\phi_{r} L^{r}$ is an AR polynomial in the lag operator $L$ and where $e_{t}$ are $N I D\left[0, \sigma^{2}\right]$. Also, linear single leading indicator models are fitted, where the linear univariate AR model (1) is augmented with lags of the leading indicator series $\left(x_{t}\right)$, so that,

$$
y_{t}=\alpha+\phi(L) y_{t}+\beta(L) x_{t}+e_{t}
$$

where $\beta(L)=\beta_{1} L+\beta_{2} L^{2}+\ldots+\beta_{K} L^{K}$.

Search algorithms were employed to derive the linear univariate AR and single leading indicator models; details of these can be found in Simpson et al. (1999). Suffice to say here that autoregressive orders up to 4 are considered in (1), while the maximum leading indicator lag considered in (2) is 8 . The principal lag selection criterion is the minimisation of the Schwartz (1978) information criterion (SIC). The optimal autoregressive lag from (1) is assumed to apply also in (2). In practice, our procedure allows intermediate leading indicator lags to be deleted, so that not all lags 1 to $K$ necessarily appear in the final specification. The empirical results provide the estimated parameter values and their standard errors, together with the values of SIC and the Akaike (1973) information criterion (AIC) for each linear specification. The probability values are provided for a number of diagnostic tests, namely the Breusch (1978) Lagrange Multiplier (LM) test for AR(4) residual autocorrelation $\left(\chi_{\mathrm{AR}}^{2}[4]\right)$, the Engle (1982) LM test for $\operatorname{ARCH}(1)\left(\chi_{\text {HET }}^{2}[1]\right)$ and Ramsey (1974) RESET test.

Multiple indicator linear models are also estimated. These are developed from the single indicator specification preferred by SIC, in order to investigate whether other leading indicators then provide additional information to improve on the single indicator forecasts.

\section{Markov Regime Switching Models}

The Hamilton (1989) two-regime Markov-switching model with AR dynamics of order $r$ may be written as:

$$
y_{t}=\mu_{0}+\mu_{1} S_{t}+\phi(L)\left\{y_{t}-\mu_{0}-\mu_{1} S_{t}\right\}+e_{t}
$$


where $S_{t} \in\{0,1\}, \phi(L)=\phi_{1} L^{1}+\phi_{2} L^{2}+\ldots+\phi_{r} L^{r}$ is a polynomial in the lag operator $L$ and $e_{t}$ are iid $\mathrm{N}\left[0, \sigma^{2}\right]$. In this specification the intercept $\left(\mu_{0}\right.$ or $\left.\mu_{0}+\mu_{1}\right)$ of the stochastic process for $y_{t}$ is a function of a binary regime variable, $S_{t}$, which represents the business cycle regime in operation at date $t$. For example, imposing the restriction $\mu_{1}>0$ identifies regime 1 as a higher growth regime than regime 0 . These regimes are frequently associated with expansions and recessions respectively. Hamilton assumed the binary regime variable, $S_{t}$, to follow a firstorder Markov process, with transition probability matrix defined in the following way:

$$
\boldsymbol{P}=\left[\begin{array}{ll}
p^{11} & p^{01} \\
p^{10} & p^{00}
\end{array}\right]
$$

The individual regime transition probabilities are defined as:

$$
\begin{aligned}
& p^{11}=\operatorname{Prob}\left[S_{t}=1 \mid S_{t-1}=1\right], \\
& p^{10}=\operatorname{Prob}\left[S_{t}=0 \mid S_{t-1}=1\right], \\
& p^{00}=\operatorname{Prob}\left[S_{t}=0 \mid S_{t-1}=0\right], \\
& p^{01}=\operatorname{Prob}\left[S_{t}=1 \mid S_{t-1}=0\right] .
\end{aligned}
$$

where $p^{10}=\left(1-p^{11}\right)$ and $p^{01}=\left(1-p^{00}\right)$. Thus, the probabilities of remaining in regime 1 and regime 0 are $p^{11}$ and $p^{00}$ respectively, while $p^{10}$ and $p^{01}$ represent the probabilities of switching from regime 1 to regime 0 and regime 0 to regime 1 respectively.

Hamilton developed an algorithm for the joint estimation of the parameters of both the switching regression model (3) and the Markov process for the regime (4). His algorithm also generates probability estimates for the latent regime variable $\left(S_{t}\right)$. Two types of probability estimates can be calculated, namely the smoothed probabilities for a specific period $t$ which use all information to the end of the sample period $T(t \leq T)$ and the filter probabilities which are based only on observations to period $t$. While the former are useful for ex-post analysis of business cycle regimes, it is the latter which are of primary interest in forecasting.

Filardo assumed the same form of switching regression model as Hamilton (1989), but extended the Markov chain component by allowing the transition probabilities to fluctuate over time with movements in an indicator variable, $x_{t}$. He uses a single indicator TVTP specification of the logistic form:

$$
\begin{aligned}
& p_{t}^{11}=\operatorname{Prob}\left[S_{t}=1 \mid S_{t-1}=1, x_{t-K_{1}}\right]=\frac{1}{1+\exp \left\{-\left(\beta_{10}+\beta_{11} x_{t-K_{1}}\right)\right\}} \\
& p_{t}^{00}=\operatorname{Prob}\left[S_{t}=0 \mid S_{t-1}=0, x_{t-K_{0}}\right]=\frac{1}{1+\exp \left\{-\left(\beta_{00}+\beta_{01} x_{t-K_{0}}\right)\right\}}
\end{aligned}
$$


where $\beta_{10}$ and $\beta_{00}$ give rise to constant transition probabilities for regime 1 and regime 0 respectively when $\beta_{11}=\beta_{01}=0$, while $\beta_{11}$ and $\beta_{01}$ are the regime 1 and regime 0 coefficients on the (respective) lagged value of the leading indicator. Thus, the probability of remaining in a regime is conditional on the lagged value of the leading indicator, $x_{t-j}$, as well as the lagged regime, $S_{t-1}$. In Simpson et al. (1999) we also apply an exponential form for the TVTP in the context of UK GDP. However, when this exponential function was applied to IOP there were many estimation problems so those results are not reported ${ }^{1}$. The logistic TVTP also produced better forecasts for IOP than the exponential specification.

In the empirical analysis the one-step ahead forecasts produced by the models are examined. The Markov-switching model's one-step ahead forecasts are calculated as:

$$
\begin{gathered}
\hat{y}_{t+1 \mid t}=\sum_{s_{t+1=0} s_{t}=0}^{1} \sum_{s_{t+1-r}=0}^{1}\left\{\hat{\mu}\left(S_{t+1}\right)+\hat{\phi}_{1}\left[y_{t}-\hat{\mu}\left(S_{t}\right)\right]+\ldots+\hat{\phi}_{r}\left[y_{t-r+1}-\hat{\mu}\left(S_{t-r+1}\right)\right]\right\} \\
\times \operatorname{Pr}\left[S_{t+1}=s_{t+1}, S_{t}=s_{t}, \ldots, S_{t-r+1}=s_{t-r+1} \mid Y_{t}, X_{t} ; \hat{\theta}\right]
\end{gathered}
$$

where $\operatorname{Pr}\left[S_{t+1}=s_{t+1}, S_{t}=s_{t}, \ldots, S_{t-r+1}=s_{t-r+1} \mid Y_{t}, X_{t} ; \hat{\theta}\right]$ is the one-step ahead predicted probability distribution of states conditional on $Y_{t}$ and $X_{t}$ which denote the set of information available on the dependent variable and the leading indicator respectively through to date $t$. This is also conditional on the vector of estimated parameters for the model, denoted by $\hat{\theta}$.

An algorithm (detailed in Simpson et al., 1999) is employed to select the Hamilton fixed transition probability (FTP) and the single indicator TVTP models. Essentially, SIC is used to select the autoregressive lag $r$ of the FTP model. This value is then assumed to apply for the TVTP specification. The TVTP leading indicator lags of $K_{1}$ and $K_{0}$ are specified by searching over all combinations within \pm 2 quarters around the lags selected in the linear specification (2). Although estimation over the full sample period caused few difficulties, the numerical algorithm sometimes broke down during the re-estimation process used to generate value forecasts and the estimation did not converge for a number of different starting parameter values. Given that one of the main aims of this paper is to assess predictive ability, then when the model is not robust to recursive re-estimation, the specification is thrown out and the next best model selected.

The empirical results provide the values of AIC and SIC for each Markov-switching specification, together with the probability values for the Filardo Likelihood-Ratio test for

\footnotetext{
${ }^{1}$ Specifically, exponential TVTP models were estimated using the treasury bill yield and the dividend yield as leading indicators, over a range of lags $K_{0}$ and $K_{l}$. Generally, these models were not robust to parameter grid search and often boundary values resulted for the transition probabilities.
} 
time-variation (L-R), along with LM tests against $\mathrm{AR}(4)\left(\chi_{\mathrm{AR}}^{2}[4]\right)$ and $\mathrm{ARCH}(1)\left(\chi_{\mathrm{HET}}^{2}[1]\right)$ disturbances. As discussed under the results below, some two indicator TVTP models were also estimated using lags derived from the selected single indicator specifications. All models, including the linear ones, were estimated in GAUSS using the non-linear BFGS optimisation algorithm.

\section{DATA}

One hundred times the logarithmic first-difference of the seasonally adjusted index of production (IOP) is employed as the dependent variable, $y_{t}$. This is shown in Figure 1 over the sample period of $1955 \mathrm{q} 2$ to $1998 \mathrm{q} 1$.

\section{Figure 1: IOP Growth}

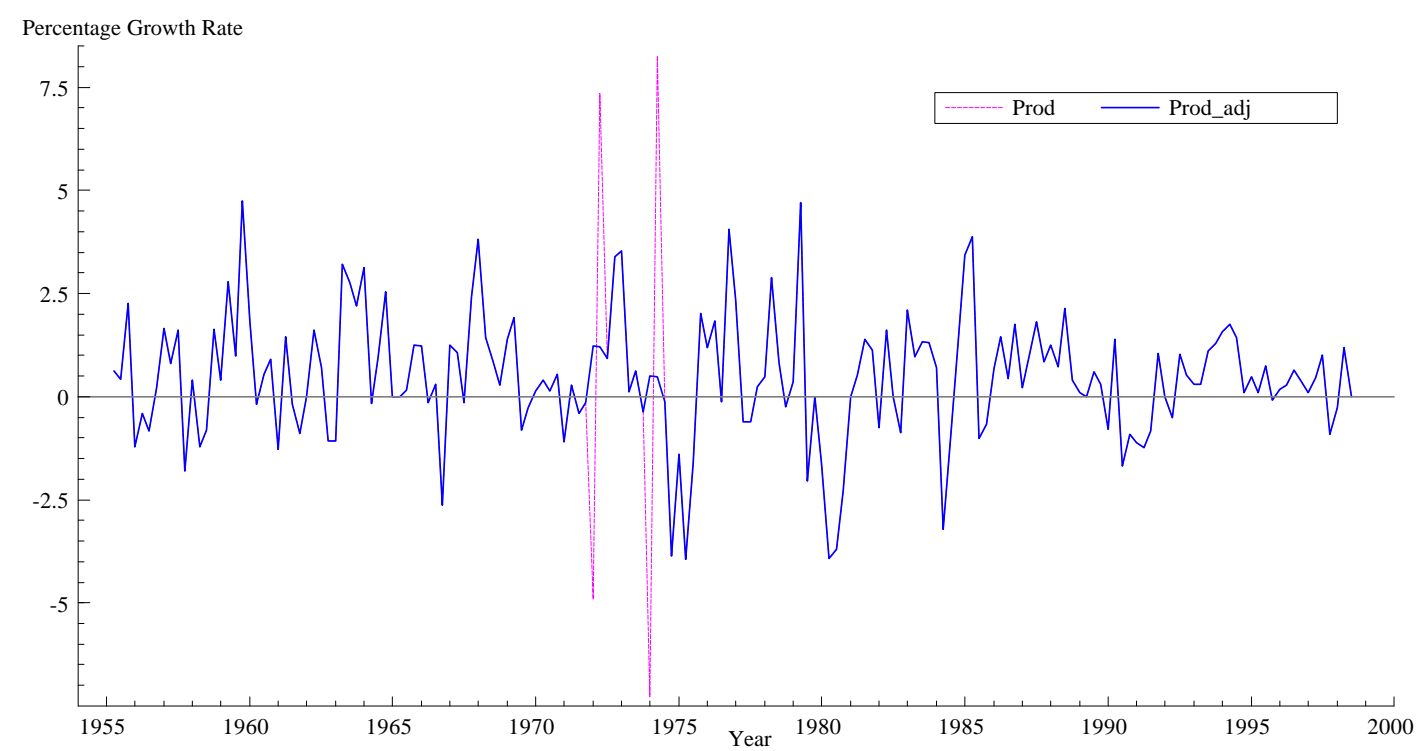

The IOP series appears to be quite noisy, even though it is seasonally adjusted and in quarterly form, with there being a number of extreme observations or outliers in the series. The outliers are identified on the basis of \pm 3 standard deviations from the mean value of IOP growth. An initial investigation revealed that these irregular observations had an adverse effect on the performance of the models. For example, both linear and non-linear models exhibited significant ARCH effects. In the case of the Markov-switching models they also appeared to be causing estimation difficulties and sometimes boundary values for the transition probabilities, with outlier observations being classified as a separate regime ${ }^{2}$. The

\footnotetext{
${ }^{2}$ The inclusion of dummy variables in the switching regression model in order to try and capture these outliers did not appear to solve these difficulties.
} 
observations identified as outliers relate to 1972q2 and 1974q1-2. The decline in 1972q2 appears to be due to a coal miner's strike and that in 1974q1-2 appears to be the result of the three day working week (see the National Institute Economic Review's Calendar of Economic Events). Since these extreme observations do not appear to be associated with genuine regime-shifts, they are removed by linear interpolation of the levels series (after taking logarithms). In general, removing these outliers led to better residual diagnostics for both the linear and non-linear Markov-switching models and improved estimation stability in the case of the TVTP specifications. The adjusted series (as a growth rate) is plotted in Figure 1, together with the unadjusted series (dotted line).

Examining Figure 1, it can be seen that there are three major recessions (as described in Dow, 1998) in IOP, with the most recent corresponding to the 1990-1992 contraction. It is also evident that the 1990-1992 downturn is less pronounced in terms of quarterly declines than the earlier contractions in IOP.

For the leading indicator series, we considered the components of the composite longer leading indicator formerly produced by Office for National Statistics ${ }^{3}$. Artis et al. (1995) found this composite indicator to provide useful predictive information for the UK business cycle. However, of the components, only the prime bank bills interest rate (IR), housing starts (HS) and CBI change in optimism (CBIO) are available for a long historical period, so these are the only components of this index used in the present study. In addition, following the stylised facts analysis of Andreou et al. (1999) we also analyse the performance of a number of financial variables in the UK for their leading properties. These are the FT actuaries all share stock price index (SP), the dividend yield of this index (DY), M0 narrow money aggregate, the 3-month treasury bill yield (TBY), a long rate (LR, dated as the 20 year yield on British government securities) and the term structure ( $\mathrm{TS}=\mathrm{LR}-\mathrm{TBY})$. These same leading indicators are also analysed in our companion paper that models GDP (Simpson et al., 1999). For more detailed data descriptions including sample period, source and graphs see the Appendix.

The indicators SP, DY, HS and M0 are transformed logarithmically prior to their use in the analysis. Most analysis is based on first differences of the leading indicators. All, with the exception of CBIO and TS, are judged to be integrated to order one by conventional Dickey Fuller unit root tests. The variables CBIO and TS are stationary according to the Dickey-Fuller tests, but we investigate the performance of the levels and first differences of these.

\footnotetext{
${ }^{3}$ The Office for National Statistics ceased producing these indicators in 1997.
} 
Prior to parameter estimation, each leading indicator is transformed to have a zero mean and standard deviation of unity over the sample period for which it is used. The longest sample period employed for the estimation and specification of the models for IOP is $1957 \mathrm{q} 1$ to 1998q1 (after allowing for differences and lagging of the data). For specific sample periods available for each leading indicator variable see the Appendix. The predictive performance of the models is then examined over the period 1990q1 to 1998q1, which is referred to as the forecast period.

\section{THE SELECTED MODELS}

In this section, we detail the model specification and provide an overall view of the models whose forecast performance we later examine.

\section{Selected Lag Lengths for Linear and TVTP Models}

The lag lengths selected for the univariate linear AR model and the Hamilton FTP model for IOP both involve a single lag of the dependent variable, so that $r=1$. Table 1 reports the selected lags for each distinct leading indicator in the single indicator linear and TVTP logistic specifications. For the TVTP model, $K_{1}^{*}$ is the lag chosen for expansion regimes and $K_{0}^{*}$ for contractions.

Table 1: Leading Indicator Lags for IOP

\begin{tabular}{|l|c|c|c|}
\hline \multicolumn{1}{|c|}{ Variable } & Linear & \multicolumn{2}{c|}{ TVTP } \\
\hline $\boldsymbol{M O}$ & $\boldsymbol{K}^{*}$ & $\boldsymbol{K}_{\mathbf{1}}^{*}$ & $\boldsymbol{K}_{\mathbf{0}}^{*}$ \\
\hline $\boldsymbol{I R}$ & 5 & 2 & 2 \\
\hline $\boldsymbol{S P}$ & 5 & 3 & 4 \\
\hline $\boldsymbol{H S}$ & 3 & 3 & 3 \\
\hline $\boldsymbol{D Y}$ & 5 & 4 & 7 \\
\hline $\boldsymbol{T B Y}$ & 3 & 3 & 1 \\
\hline LR & 5,7 & 8 & 6 \\
\hline Level TS & 3 & 3 & 3 \\
\hline Difference $\boldsymbol{T S}$ & 4 & 6 & 4 \\
\hline Level CBIO & 7 & 5 & 6 \\
\hline Difference CBIO & 1 & $\mathrm{n} / \mathrm{a}$ & $\mathrm{n} / \mathrm{a}$ \\
\hline
\end{tabular}

It might be noted that, although the procedure allows for multiple lags in the linear specification, in practice multiple lags are selected only for the treasury bill yield. No lag 
specification is included in Table 1 for a TVTP specification using the level of CBIO because no satisfactory model could be found.

\section{Estimation and Diagnostic Test Results}

First of all we briefly examine the linear model estimation and diagnostic test results presented in Table 2. The LM residual diagnostics for the linear univariate AR(1) specification do not show strong evidence of model mis-specification, although there is a hint of heteroscedasticity and/or non-linearity in that the $\chi_{\text {HET [1] }}^{2}$ and RESET p-values are around 0.1. When the leading indicators are introduced, only the models involving M0 and housing starts are not chosen by SIC over the simple univariate AR(1) specification. On the basis of SIC (or AIC), the dividend yield (DY) is the best leading indicator. Also, the difference of the term structure is preferred over its level, but for CBIO the level is preferred. RESET indicates that the specifications with a greater RESET statistic p-value than the linear AR(1) model are perhaps capturing more of the non-linearities in industrial production. Notice the very high RESET p-value for the level of CBI optimism balance (CBIO), suggesting no nonlinearities are present in this specification.

A variation on the linear indicator model was tried by adding further indicators. As the DY linear model has the lowest SIC then each variable ${ }^{4}$ was added in turn to this model creating a linear model with two leading indicators. Note that the variables were incorporated at the lags selected in the individual indicator analysis. From Table 3 it may be seen that the specification involving DY and TBY (with only lag 5 and not 7, which becomes insignificant) is the best two-indicator model according to SIC, and this is preferred over the model involving only DY. The second best model, involving DY and CBIO, is also selected over the DY specification. Since, compared with the single indicator models, adding either TBY or CBIO to DY leads to a preferred specification, a three-indicator with these variables is also presented in Table 3. Again the second lag of TBY appears to be redundant and the model with one lag of each variable is the best of those considered according to SIC. Had model choice been based on AIC, then this would again be the selected linear specification.

The three-indicator model in the final column of Table 3 implies a strong role for each in modelling industrial production. As anticipated, increases in short-term interest rates (measured as the treasury bill yield) imply declines in industrial production, with increases in

\footnotetext{
${ }^{4} \mathrm{M} 0$ was not considered here due to its poor performance in the single indicator investigation. IR was also not examined because it is similar to TBY and TBY has a lower SIC than IR. Similarly, for TS and $\mathrm{CBIO}$, the difference and the level respectively are used since these are the preferred specifications for these variables in Table 1.
} 
the dividend yield having a similar effect; the lags on these are 5 and 3 quarters respectively. The CBI measure of optimism has a positive sign at a lag of one quarter. However, one interesting interpretation of the results for this model is that, at least in relation to movements in industrial production, the optimism measure does not incorporate fully all known information since longer lags of financial variables retain important roles. It is also worthy of note that, although all our models maintain the autoregressive term, this coefficient is not significant at the 5 percent level for the models including the CBIO level and this lack of significance is even more notable in the two and three-indicator models including this variable. Thus, these latter models appear to explain the univariate dynamics of IOP.

The sign and significance of the intercepts for the Hamilton FTP model in Table 4 indicate "classical" business cycle behaviour. The data can be classified into positive and negative growth rate regimes, with an intercept of .67 per quarter in regime 1 (expansion) and -2.41 in regime 0 (contraction). These values indicate an asymmetry, with the implied rate of growth in contractions being on average substantially greater in absolute value than in expansions. The transition probability estimates also indicate an asymmetry in the persistence of expansion and contraction regimes. The values for the constant expansion-to-expansion and recession-to-recession transition probabilities imply that on average the economy is more likely to remain in an expansion than in a recession phase of the cycle. Thus, the FTP model estimates show contractions to be sharper and shorter than expansions. Similar asymmetries have been reported to be a feature of monthly UK IOP by Artis et al. (1997). The LM tests for first-order heteroscedasticity and fourth-order serial correlation give no sign of model misspecification. Note that the model selection criteria AIC and SIC cannot be compared with the linear AR specification as an indication of regime switching non-linearity because of the non-standard testing conditions that are involved (see Hamilton and Perez-Quiros, 1996).

The TVTP results for the single indicator and two cases with two indicators are also shown in Table 4. The estimates of the regime dependent intercepts associated with the TVTP logistic estimations are statistically significant and again indicate "classical" business cycle behaviour in IOP. According to SIC, the difference of the term structure (TS) provides the best single indicator specification in this context and has a lower SIC than the Hamilton FTP model. Although all the other models have higher SIC than the FTP model, there is still a fair amount of support for time-variation. In particular, AIC favours the TVTP specification for most variables, while the Filardo Likelihood Ratio (L-R) test for the null hypothesis of constant transition probabilities produces probability value of around $5 \%$ or less for a number of leading indicators, providing additional evidence in favour of time variation. The residual diagnostic tests are generally satisfactory. 
The signs of the parameters across the various TVTP logistic specifications appear to be generally economically sensible. With the single exception of the specification using the level of the term structure, the sign of the estimate of $\beta_{11}$ is the same as the sign of the slope coefficient in the corresponding linear model. Thus, during expansions, movements in the leading indicator have a similar interpretation in terms of direction of change of IOP as in the linear case. For this interpretation to carry over to contractions, the sign of the estimate of $\beta_{01}$ should be opposite to that of the linear model, and this is the case, except for DY and (the first difference of) CBIO. Their size and significance also suggest that a number of variables provide different amounts of information about expansions and contractions. The mean of the expansion-to-expansion transition probability (denoted by $\bar{p}^{11}$ and obtained by setting the conditioning information to zero) is approximately the same as that of the FTP specification for all variables. On the other hand, the mean of the recession-to-recession probability sometimes differs substantially from that of FTP. For example, the prime bank bills interest rate (IR), this is .933 compared with .706 for FTP. Thus, when no information is provided by IR $\left(x_{t}=0\right)$ there is on average a 93\% chance of remaining in a recession regime. This probability declines with decreases in the interest rate, and IOP is more likely to exit recession for larger interest rate decreases.

Two-indicator TVTP models were also considered. Both such models shown in Table 4 use IR as the leading indicator during contractions (regime 0), since in terms both of the magnitude and significance of its estimated slope coefficient $\beta_{01}$ this variable apparently provides most leading indicator information in this regime. During expansions (regime 1), the difference of TS and also housing starts (HS) are considered, the former having the largest and most significant slope coefficient in that regime with the latter also having a highly significant coefficient. Due to estimation difficulties encountered when the logistic TVTP specification involves a single slope coefficient within a regime, no attempt is made to add an additional leading indicator in the logistic function of (5).

Neither two-indicator TVTP specification is very successful. In both cases, IR is insignificant in the recession probabilities. Also, both SIC and AIC still point to the singleindicator difference TS model as the preferred TVTP specification. A few other specifications were also tried, but yielded no improvements on those reported.

\section{Regime Classifications}

As mentioned in the Introduction, one attraction of the use of Markov-switching models in the analysis of business cycles is that they are capable of providing explicit information about the 
regime. We illustrate the regime classification performance of our Markov-switching models in Figure 2, where we show the filter probabilities of regime 0 (recession) generated from the FTP and the TVTP logistic models for each indicator series, where the TS model uses the differences. These probabilities are generated from the estimated models and employ all sample data. The shaded areas in this figure (DRec) represent recessionary regimes for UK IOP as dated by Artis et al. (1997). Hence, the shading provides some benchmark for the performance of the models of Table 4 in terms of capturing historical recessions.

A few points about Figure 2 are worth noting. Firstly, although Artis et al. date recessions around 1967 and 1971, neither is well detected by the models since the recession probabilities generally do not exceed .5 during these periods (apart from TBY briefly). This is particularly true for the latter recession. However, all Markov-switching models capture the major recessions of the mid-1970s and the early 1980s. Many also provide some evidence of a mid-1980s recession in IOP. However, the majority of models produce only a weak signal of a recession during 1990-1992. Only the TVTP specification for prime bank interest rates (IR) seem to provide a strong indication of a contraction during the 1990s.

The FTP model itself provides very little evidence of this last recession. Essentially, the reason appears to be that the two-regime Markov-switching models of Table 4 associate recession with very strong quarterly declines in industrial production. Although the 1990s recession evidenced a sustained period of production declines, it did not contain any single quarter with a decline of the magnitude seen in each of the three previous IOP recessions (mid-1970, early 1980s and mid-1980s). Indeed, if we accept the judgement of Artis et al. (1997) that an industrial production recession occurred in the UK around 1971, it is also clear from Figure 1 that this recession does not contain a quarter of large enough decline. This may also explain the failure of the Markov-switching models to detect this earlier recession.

In summary, the linear models' estimation and test results imply that DY is the most useful single indicator variable for IOP. A combination of three indicators (DY, TBY and CBIO) achieves the lowest SIC of all linear models considered. The results of the Markovswitching estimations lend support for "classical" cycles and cyclical asymmetries in IOP. The findings show support for time-variation between business cycle phases. In particular, out of the indicators considered the difference of the interest rate term structure appears to perform well at fitting IOP growth. Overall, the univariate Hamilton model appears to require strong evidence of recession in the form of a sharp decline in order to provide reliable regime classification for industrial production. However, prime bank bills interest rates appear to be useful in helping to classify the 1990s recession. We anticipate that this last finding will be reflected in improved value forecasts over this period, which are dealt with in the next section. 
Table 2: Linear Models for IOP with one Leading Indicator

\begin{tabular}{|c|c|c|c|c|c|c|c|c|c|c|c|c|}
\hline & & \multicolumn{11}{|c|}{ Leading Indicators } \\
\hline & $A R(1)^{*}$ & MO & $I R$ & $S P$ & $H S$ & $D Y$ & $T B Y$ & $L R$ & Level TS & Diff $T S$ & $\begin{array}{l}\text { Level } \\
\text { CBIO }\end{array}$ & $\begin{array}{c}\text { Diff } \\
\text { CBIO }\end{array}$ \\
\hline$\alpha$ & $\begin{array}{c}.298 \\
(.118) \\
\end{array}$ & $\begin{array}{c}.233 \\
(.146) \\
\end{array}$ & $\begin{array}{c}.322 \\
(.116) \\
\end{array}$ & $\begin{array}{c}.278 \\
(.119) \\
\end{array}$ & $\begin{array}{c}.307 \\
(.116)\end{array}$ & $\begin{array}{c}.284 \\
(.122) \\
\end{array}$ & $\begin{array}{c}.320 \\
(.120)\end{array}$ & $\begin{array}{c}.314 \\
(.115) \\
\end{array}$ & $\begin{array}{r}.317 \\
(.122) \\
\end{array}$ & $\begin{array}{c}.296 \\
(.121) \\
\end{array}$ & $\begin{array}{c}.401 \\
(.120) \\
\end{array}$ & $\begin{array}{c}.323 \\
(.119) \\
\end{array}$ \\
\hline$\sigma$ & $\begin{array}{l}1.403 \\
(.069) \\
\end{array}$ & $\begin{array}{l}1.451 \\
(.092) \\
\end{array}$ & $\begin{array}{l}1.358 \\
(.071) \\
\end{array}$ & $\begin{array}{l}1.334 \\
(.075) \\
\end{array}$ & $\begin{array}{l}1.385 \\
(.071) \\
\end{array}$ & $\begin{array}{l}1.329 \\
(.076) \\
\end{array}$ & $\begin{array}{l}1.325 \\
(.074) \\
\end{array}$ & $\begin{array}{l}1.357 \\
(.071) \\
\end{array}$ & $\begin{array}{l}1.371 \\
(.074) \\
\end{array}$ & $\begin{array}{l}1.362 \\
(.073) \\
\end{array}$ & $\begin{array}{l}1.342 \\
(.071) \\
\end{array}$ & $\begin{array}{l}1.368 \\
(.072) \\
\end{array}$ \\
\hline$\phi_{1}$ & $\begin{array}{c}.329 \\
(.074)\end{array}$ & $\begin{array}{c}.351 \\
(.089)\end{array}$ & $\begin{array}{c}.278 \\
(.072)\end{array}$ & $\begin{array}{c}.290 \\
(.083)\end{array}$ & $\begin{array}{c}.310 \\
(.079)\end{array}$ & $\begin{array}{c}.275 \\
(.075)\end{array}$ & $\begin{array}{c}.298 \\
(.074)\end{array}$ & $\begin{array}{c}.295 \\
(.072)\end{array}$ & $\begin{array}{c}.305 \\
(.087)\end{array}$ & $\begin{array}{c}.347 \\
(.079)\end{array}$ & $\begin{array}{c}.153 \\
(.106)\end{array}$ & $\begin{array}{c}.316 \\
(.079)\end{array}$ \\
\hline$\beta_{1}$ & -- & $\begin{array}{c}-.185 \\
(.128)\end{array}$ & $\begin{array}{c}.360 \\
(.097) \\
\end{array}$ & $\begin{array}{c}.486 \\
(.115)\end{array}$ & $\begin{array}{c}.227 \\
(.107)\end{array}$ & $\begin{array}{c}-.504 \\
(.104)\end{array}$ & $\begin{array}{c}-.381 \\
(.103)\end{array}$ & $\begin{array}{c}.359 \\
(.098)\end{array}$ & $\begin{array}{c}.304 \\
(.119)\end{array}$ & $\begin{array}{c}.331 \\
(.108)\end{array}$ & $\begin{array}{c}.542 \\
(.145)\end{array}$ & $\begin{array}{c}.374 \\
(.108)\end{array}$ \\
\hline$\beta_{2}$ & -- & -- & -- & -- & -- & -- & $\begin{array}{c}-.263 \\
(.103) \\
\end{array}$ & -- & -- & -- & -- & -- \\
\hline $\mathbf{L}_{\mathbf{T}}(\boldsymbol{\theta})$ & -127.43 & -89.84 & -122.52 & -100.89 & -125.47 & -100.44 & -108.57 & -122.43 & -113.369 & -112.48 & -114.39 & -117.15 \\
\hline AIC & 1.716 & 1.822 & 1.665 & 1.639 & 1.704 & 1.632 & 1.634 & 1.664 & 1.689 & 1.676 & 1.644 & 1.683 \\
\hline SIC & 1.776 & 1.924 & 1.744 & 1.728 & 1.783 & 1.721 & 1.740 & 1.743 & 1.773 & 1.760 & 1.727 & 1.765 \\
\hline$\chi_{\mathrm{AR}}^{2}[4]$ & .885 & .822 & .535 & .688 & .978 & .369 & .270 & .737 & .999 & .170 & .111 & .429 \\
\hline$\chi_{\mathrm{HET}}^{2}[1]$ & .127 & .304 & .091 & .018 & .109 & .032 & .986 & .020 & .096 & .623 & .128 & .014 \\
\hline RESET & .102 & .211 & .313 & .109 & .063 & .171 & .345 & .022 & . 107. & .241 & .745 & .004 \\
\hline
\end{tabular}

Notes : $\alpha$ is the intercept, $\sigma$ is the standard error of the regression and $\phi_{I}$ is the coefficient on the lag of production. $\beta_{i}$ represents the coefficient on the $i$-th regressor (not the coefficient on the $i$-th lag, see Table 1 for the appropriate lag). Standard errors are given inside parentheses. $L_{\mathrm{T}}(\boldsymbol{\theta})$ is the sample conditional $\log$-likelihood value (excluding the constant $2 \pi$ term). *Estimated over the sample period starting in $1960 \mathrm{q} 2$. 
Table 3: Linear Models for IOP with more than one Leading Indicator

\begin{tabular}{|c|c|c|c|c|c|c|c|c|c|c|}
\hline & \multicolumn{10}{|c|}{ Leading Indicators } \\
\hline & $D Y$ & $D Y, S P$ & $D Y, H S$ & $\begin{array}{c}D Y, T B Y \\
(1) \\
\end{array}$ & $\begin{array}{c}D Y, T B Y \\
(2) \\
\end{array}$ & $D Y, L R$ & $D Y, T S$ & $D Y, C B I O$ & $\begin{array}{c}D Y, C B I O, T B Y \\
(1)\end{array}$ & $\begin{array}{c}D Y, C B I O, T B Y \\
\text { (2) }\end{array}$ \\
\hline$\alpha$ & $\begin{array}{l}.284 \\
(.122)\end{array}$ & $\begin{array}{l}.285 \\
(.124)\end{array}$ & $\begin{array}{l}.292 \\
(.121)\end{array}$ & $\begin{array}{l}.302 \\
(.117)\end{array}$ & $\begin{array}{l}.300 \\
(.117)\end{array}$ & $\begin{array}{l}.286 \\
(.121)\end{array}$ & $\begin{array}{c}.303 \\
(.119)\end{array}$ & $\begin{array}{l}.345 \\
(.119)\end{array}$ & $\begin{array}{l}.350 \\
(.115)\end{array}$ & $\begin{array}{c}.351 \\
(.115)\end{array}$ \\
\hline$\sigma$ & $\begin{array}{l}1.329 \\
(.076)\end{array}$ & $\begin{array}{l}1.329 \\
(.090)\end{array}$ & $\begin{array}{l}1.319 \\
(.077)\end{array}$ & $\begin{array}{l}1.263 \\
(.075)\end{array}$ & $\begin{array}{l}1.272 \\
(.075)\end{array}$ & $\begin{array}{l}1.323 \\
(.076)\end{array}$ & $\begin{array}{l}1.304 \\
(.077)\end{array}$ & $\begin{array}{l}1.274 \\
(.076)\end{array}$ & $\begin{array}{l}1.227 \\
(.078)\end{array}$ & $\begin{array}{l}1.228 \\
(.075)\end{array}$ \\
\hline$\phi_{1}$ & $\begin{array}{l}.275 \\
(.075) \\
\end{array}$ & $\begin{array}{l}.274 \\
(.090) \\
\end{array}$ & $\begin{array}{l}.255 \\
(.082) \\
\end{array}$ & $\begin{array}{c}.231 \\
(.072) \\
\end{array}$ & $\begin{array}{l}.238 \\
(.072) \\
\end{array}$ & $\begin{array}{l}.272 \\
(.075) \\
\end{array}$ & $\begin{array}{l}.229 \\
(.085) \\
\end{array}$ & $\begin{array}{l}.128 \\
(.104) \\
\end{array}$ & $\begin{array}{l}.115 \\
(.104) \\
\end{array}$ & $\begin{array}{l}.111 \\
(.100) \\
\end{array}$ \\
\hline$\beta_{1}$ & $\begin{array}{l}-.504 \\
(.104) \\
\end{array}$ & $\begin{array}{l}-.556 \\
(.133) \\
\end{array}$ & $\begin{array}{l}-.499 \\
(.104) \\
\end{array}$ & $\begin{array}{l}-.456 \\
(.109) \\
\end{array}$ & $\begin{array}{l}-.484 \\
(.104) \\
\end{array}$ & $\begin{array}{l}-.416 \\
(.136) \\
\end{array}$ & $\begin{array}{l}-.478 \\
(.102) \\
\end{array}$ & $\begin{array}{l}-.420 \\
(.100) \\
\end{array}$ & $\begin{array}{l}-.406 \\
(.106) \\
\end{array}$ & $\begin{array}{l}-.411 \\
(.100) \\
\end{array}$ \\
\hline$\beta_{2}$ & -- & $\begin{array}{l}-.053 \\
(.146) \\
\end{array}$ & $\begin{array}{l}.173 \\
(.115) \\
\end{array}$ & $\begin{array}{l}-.393 \\
(.105) \\
\end{array}$ & $\begin{array}{l}-.392 \\
(.104) \\
\end{array}$ & $\begin{array}{l}-.162 \\
(.137) \\
\end{array}$ & $\begin{array}{l}.272 \\
(.118) \\
\end{array}$ & $\begin{array}{c}.458 \\
(.143) \\
\end{array}$ & $\begin{array}{c}.386 \\
(.142) \\
\end{array}$ & $\begin{array}{c}.406 \\
(.138) \\
\end{array}$ \\
\hline$\beta_{3}$ & & -- & -- & $\begin{array}{l}-.157 \\
(.109) \\
\end{array}$ & -- & -- & -- & -- & $\begin{array}{l}-.351 \\
(.102) \\
\end{array}$ & $\begin{array}{l}-.349 \\
(.101) \\
\end{array}$ \\
\hline$\beta_{4}$ & & -- & -- & -- & -- & -- & -- & -- & $\begin{array}{l}-.051 \\
(.109) \\
\end{array}$ & -- \\
\hline $\mathbf{L}_{\mathrm{T}}(\boldsymbol{\theta})$ & -100.44 & -100.44 & -99.39 & -93.89 & -94.83 & -99.78 & -97.95 & -95.02 & -90.19 & -90.29 \\
\hline AIC & 1.632 & 1.647 & 1.631 & 1.561 & 1.560 & 1.637 & 1.609 & 1.563 & 1.519 & 1.504 \\
\hline SIC & 1.721 & 1.759 & 1.743 & 1.695 & 1.671 & 1.749 & 1.720 & 1.674 & 1.675 & 1.638 \\
\hline$\chi_{\mathrm{AR}}^{2}[4]$ & .369 & .345 & .321 & .373 & .589 & .469 & .607 & .093 & .114 & .061 \\
\hline$\chi_{\text {HET }}^{2}[1]$ & .032 & .034 & .040 & .338 & .140 & .017 & .040 & .025 & .087 & .124 \\
\hline RESET & .171 & .181 & .139 & .392 & .498 & .066 & .123 & .592 & .243 & .277 \\
\hline
\end{tabular}


Table 4: FTP and TVTP Models for IOP

\begin{tabular}{|c|c|c|c|c|c|c|c|c|c|c|c|c|c|}
\hline & & \multicolumn{12}{|c|}{ TVTP } \\
\hline & $F T P^{*}$ & MO & $I R$ & $S P$ & $H S$ & $D Y$ & $T B Y$ & $L R$ & Level TS & Diff $T S$ & $\begin{array}{c}\text { Diff } \\
\text { CBIO }\end{array}$ & $T S, I R$ & $H S, I R$ \\
\hline$\mu_{0}+\mu_{1}$ & $\begin{array}{c}.670 \\
(.129) \\
\end{array}$ & $\begin{array}{c}.700 \\
(.158) \\
\end{array}$ & $\begin{array}{c}.720 \\
(.141) \\
\end{array}$ & $\begin{array}{c}.674 \\
(.163) \\
\end{array}$ & $\begin{array}{c}.656 \\
(.121) \\
\end{array}$ & $\begin{array}{c}.625 \\
(.146) \\
\end{array}$ & $\begin{array}{c}.686 \\
(.165) \\
\end{array}$ & $\begin{array}{c}.681 \\
(.134) \\
\end{array}$ & $\begin{array}{c}.698 \\
(.139) \\
\end{array}$ & $\begin{array}{c}.683 \\
(.136) \\
\end{array}$ & $\begin{array}{c}.676 \\
(.133) \\
\end{array}$ & $\begin{array}{c}.685 \\
(.137) \\
\end{array}$ & $\begin{array}{c}.654 \\
(.126) \\
\end{array}$ \\
\hline$\mu_{0}$ & $\begin{array}{l}-2.412 \\
(.531) \\
\end{array}$ & $\begin{array}{l}-2.402 \\
(.507) \\
\end{array}$ & $\begin{array}{r}-1.671 \\
(.612) \\
\end{array}$ & $\begin{array}{c}-2.300 \\
(.630) \\
\end{array}$ & $\begin{array}{r}-2.524 \\
(.561) \\
\end{array}$ & $\begin{array}{l}-2.587 \\
(.543) \\
\end{array}$ & $\begin{array}{l}-2.519 \\
(.782) \\
\end{array}$ & $\begin{array}{l}-2.333 \\
(.571) \\
\end{array}$ & $\begin{array}{c}-2.440 \\
(.523)\end{array}$ & $\begin{array}{l}-2.567 \\
(.510) \\
\end{array}$ & $\begin{array}{c}-2.532 \\
(.561)\end{array}$ & $\begin{array}{r}-2.477 \\
(.553) \\
\end{array}$ & $\begin{array}{c}-2.438 \\
(.682) \\
\end{array}$ \\
\hline$\phi_{1}$ & $\begin{array}{c}.206 \\
(.066) \\
\end{array}$ & $\begin{array}{c}.207 \\
(.086) \\
\end{array}$ & $\begin{array}{c}.192 \\
(.064) \\
\end{array}$ & $\begin{array}{c}.213 \\
(.073) \\
\end{array}$ & $\begin{array}{c}.162 \\
(.071) \\
\end{array}$ & $\begin{array}{c}.275 \\
(.077) \\
\end{array}$ & $\begin{array}{c}.202 \\
(.068) \\
\end{array}$ & $\begin{array}{c}.205 \\
(.066) \\
\end{array}$ & $\begin{array}{c}.254 \\
(.066) \\
\end{array}$ & $\begin{array}{c}.242 \\
(.065) \\
\end{array}$ & $\begin{array}{c}.213 \\
(.071) \\
\end{array}$ & $\begin{array}{c}.244 \\
(.065) \\
\end{array}$ & $\begin{array}{c}.168 \\
(.070) \\
\end{array}$ \\
\hline$\sigma$ & $\begin{array}{l}1.232 \\
(.060)\end{array}$ & $\begin{array}{l}1.221 \\
(.069)\end{array}$ & $\begin{array}{l}1.258 \\
(.064)\end{array}$ & $\begin{array}{l}1.214 \\
(.067)\end{array}$ & $\begin{array}{l}1.236 \\
(.059)\end{array}$ & $\begin{array}{l}1.180 \\
(.070)\end{array}$ & $\begin{array}{l}1.219 \\
(.071)\end{array}$ & $\begin{array}{l}1.230 \\
(.059)\end{array}$ & $\begin{array}{l}1.225 \\
(.060)\end{array}$ & $\begin{array}{l}1.238 \\
(.054)\end{array}$ & $\begin{array}{l}1.267 \\
(.058)\end{array}$ & $\begin{array}{l}1.239 \\
(.055)\end{array}$ & $\begin{array}{l}1.244 \\
(.059)\end{array}$ \\
\hline$\beta_{10}$ & $\begin{array}{l}3.755 \\
(.454) \\
\end{array}$ & $\begin{array}{l}3.323 \\
(.660) \\
\end{array}$ & $\begin{array}{c}4.324 \\
(1.378) \\
\end{array}$ & $\begin{array}{l}3.905 \\
(.703) \\
\end{array}$ & $\begin{array}{l}4.531 \\
(.717) \\
\end{array}$ & $\begin{array}{l}3.638 \\
(.830) \\
\end{array}$ & $\begin{array}{c}4.324 \\
(1.693) \\
\end{array}$ & $\begin{array}{c}4.805 \\
(1.271) \\
\end{array}$ & $\begin{array}{c}4.598 \\
(1.146) \\
\end{array}$ & $\begin{array}{l}8.032 \\
(.978) \\
\end{array}$ & $\begin{array}{l}4.996 \\
(.989) \\
\end{array}$ & $\begin{array}{l}7.600 \\
(.848) \\
\end{array}$ & $\begin{array}{l}4.495 \\
(.791) \\
\end{array}$ \\
\hline$\beta_{11}$ & -- & $\begin{array}{c}-.301 \\
(.671) \\
\end{array}$ & $\begin{array}{c}-1.195 \\
(.891) \\
\end{array}$ & $\begin{array}{l}1.178 \\
(.518) \\
\end{array}$ & $\begin{array}{l}1.300 \\
(.410) \\
\end{array}$ & $\begin{array}{c}-1.382 \\
(.532) \\
\end{array}$ & $\begin{array}{r}-1.347 \\
(.838) \\
\end{array}$ & $\begin{array}{r}-1.748 \\
(.853) \\
\end{array}$ & $\begin{array}{r}-1.363 \\
(.911) \\
\end{array}$ & $\begin{array}{l}2.770 \\
(.447) \\
\end{array}$ & $\begin{array}{l}1.169 \\
(.488) \\
\end{array}$ & $\begin{array}{l}2.648 \\
(.435) \\
\end{array}$ & $\begin{array}{l}1.261 \\
(.427) \\
\end{array}$ \\
\hline$\beta_{00}$ & $\begin{array}{c}.876 \\
(.437) \\
\end{array}$ & $\begin{array}{c}.392 \\
(.839) \\
\end{array}$ & $\begin{array}{l}2.629 \\
(.741) \\
\end{array}$ & $\begin{array}{c}.849 \\
(1.065) \\
\end{array}$ & $\begin{array}{c}.562 \\
(.761) \\
\end{array}$ & $\begin{array}{l}-.475 \\
(.875) \\
\end{array}$ & $\begin{array}{c}.252 \\
(.894) \\
\end{array}$ & $\begin{array}{l}1.318 \\
(.612) \\
\end{array}$ & $\begin{array}{l}1.009 \\
(.578) \\
\end{array}$ & $\begin{array}{c}1.245 \\
(1.094) \\
\end{array}$ & $\begin{array}{l}2.053 \\
(.880) \\
\end{array}$ & $\begin{array}{l}1.018 \\
(.884) \\
\end{array}$ & $\begin{array}{c}.659 \\
(.736) \\
\end{array}$ \\
\hline$\beta_{01}$ & -- & $\begin{array}{c}.958 \\
(.841) \\
\end{array}$ & $\begin{array}{l}4.344 \\
(.899) \\
\end{array}$ & $\begin{array}{l}-1.326 \\
(1.119)\end{array}$ & $\begin{array}{c}-1.110 \\
(.841) \\
\end{array}$ & $\begin{array}{r}-1.525 \\
(.975) \\
\end{array}$ & $\begin{array}{c}2.986 \\
(1.110)\end{array}$ & $\begin{array}{l}1.189 \\
(.646)\end{array}$ & $\begin{array}{l}-.350 \\
(.593)\end{array}$ & $\begin{array}{l}-1.244 \\
(1.221)\end{array}$ & $\begin{array}{l}1.126 \\
(.965)\end{array}$ & $\begin{array}{c}.393 \\
(1.193)\end{array}$ & $\begin{array}{c}.347 \\
(1.088)\end{array}$ \\
\hline $\bar{p}^{11}$ & .977 & .965 & .987 & .980 & .989 & .974 & .987 & .992 & .990 & .999 & .993 & .999 & .989 \\
\hline $\bar{p}^{00}$ & .706 & .597 & .933 & .700 & .637 & .383 & .563 & .789 & .733 & .777 & .886 & .735 & .659 \\
\hline $\mathbf{L}_{\mathbf{T}}(\boldsymbol{\theta})$ & -122.78 & -85.77 & -120.82 & -100.26 & -119.82 & -100.74 & -108.79 & -118.18 & -110.14 & -105.67 & -113.54 & -106.79 & -120.82 \\
\hline AIC & 1.695 & 1.821 & 1.695 & 1.692 & 1.682 & 1.699 & 1.680 & 1.660 & 1.700 & 1.636 & 1.688 & 1.652 & 1.695 \\
\hline SIC & 1.814 & 2.025 & 1.854 & 1.870 & 1.841 & 1.877 & 1.849 & 1.819 & 1.869 & 1.804 & 1.853 & 1.821 & 1.854 \\
\hline L-R & -- & .419 & .139 & .022 & .051 & .035 & .055 & .010 & .209 & .002 & .016 & .007 & .139 \\
\hline$\chi_{\mathrm{AR}}^{2}[4]$ & .354 & .826 & .275 & .301 & .154 & .666 & .138 & .371 & .392 & .589 & .320 & .569 & .160 \\
\hline$\chi_{\text {HET }}^{2}[1]$ & .186 & .249 & .931 & .522 & .940 & .804 & .071 & .797 & .005 & .336 & .454 & .333 & .953 \\
\hline
\end{tabular}


Figure 2: FTP and TVTPs Recession Probabilities
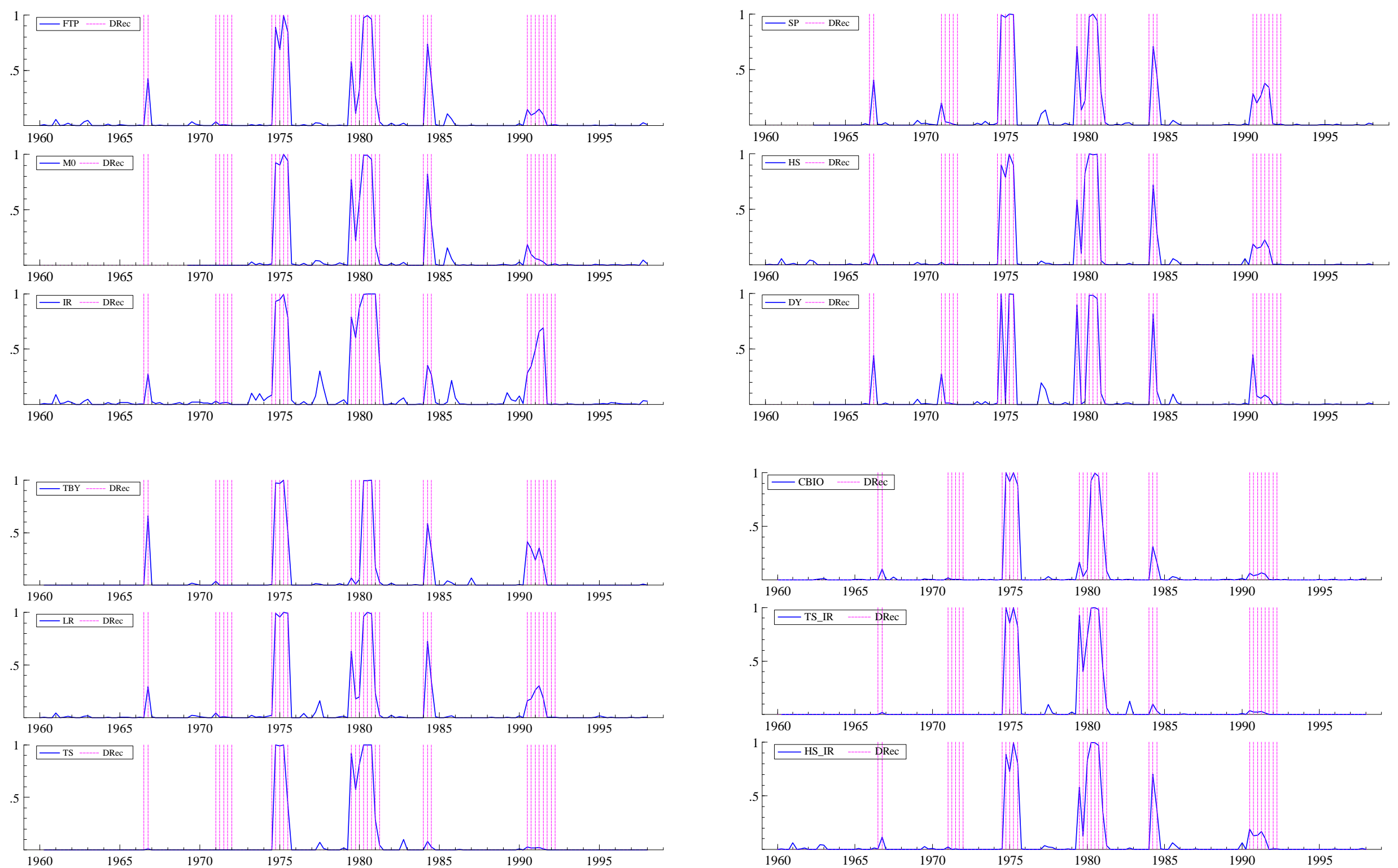
Table 5: Linear and Non-linear Models Forecast Results

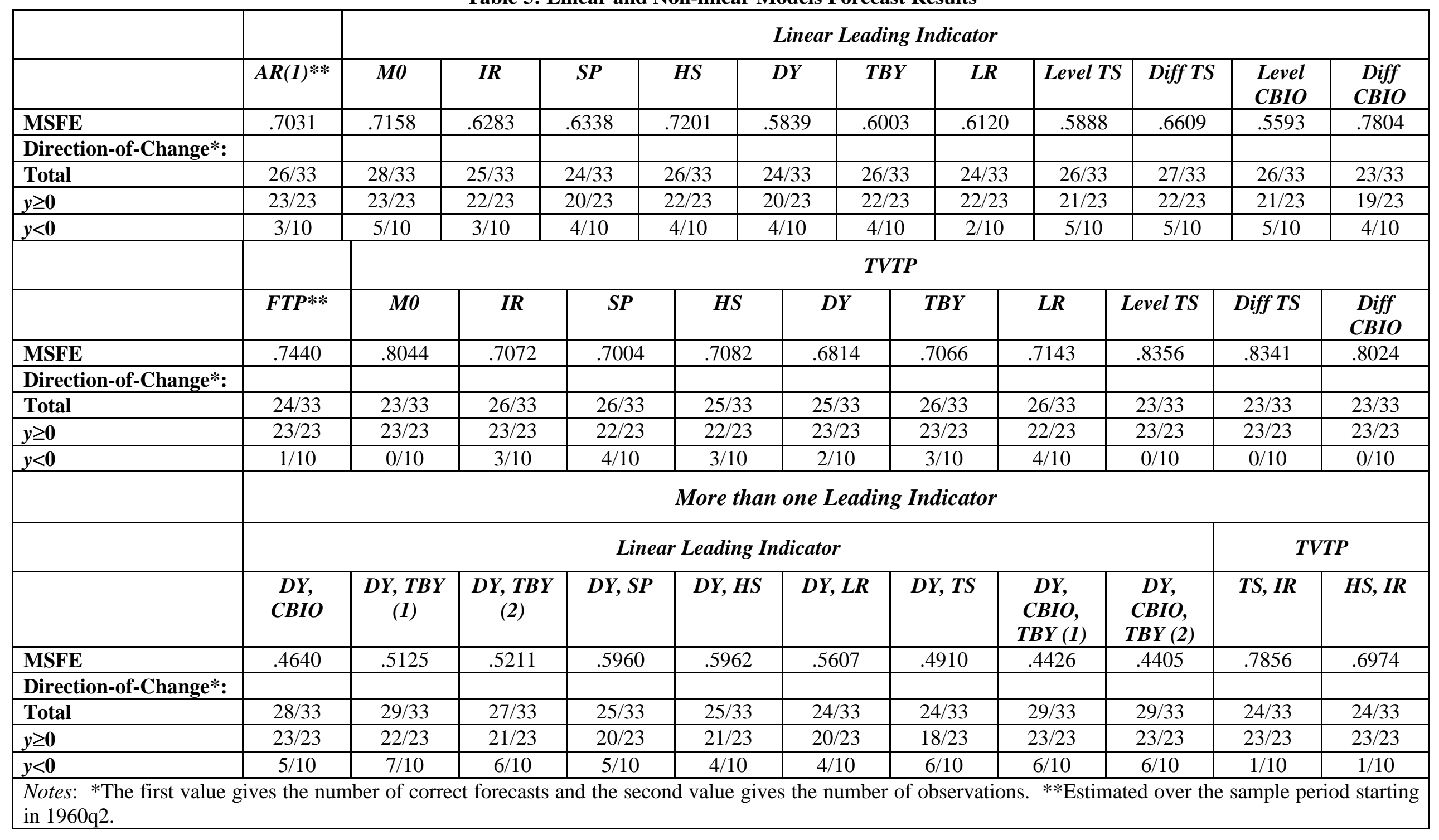


Figure 3: One-Step Ahead Forecasts
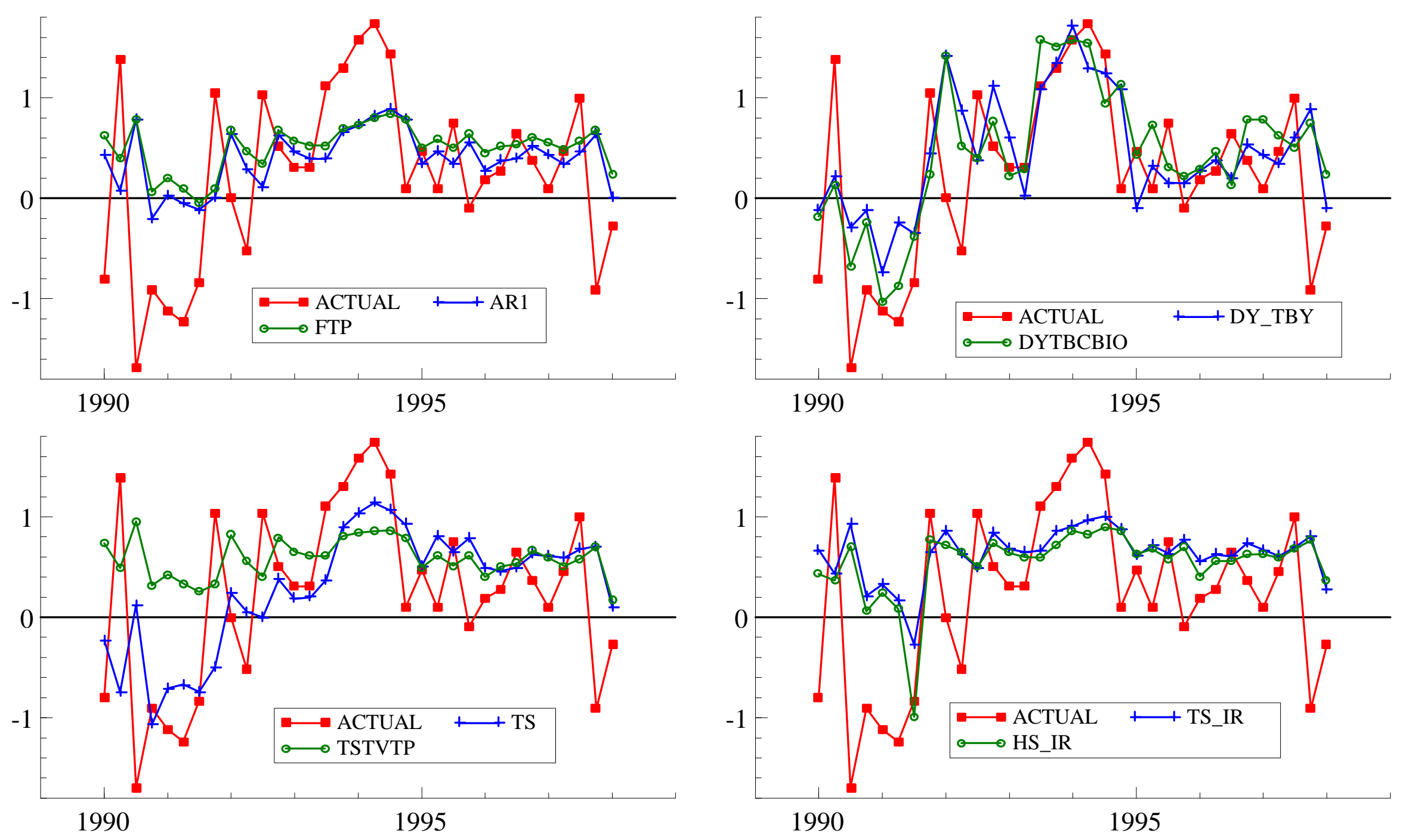


\section{FORECAST RESULTS}

In this section the one-step ahead forecasts for industrial production growth of the linear and non-linear Markov-switching regime specifications are examined. The forecast period covers the last thirty three quarters of the sample, 1990q1 to 1998q1, which includes the 1990-1992 contraction. It should be noted that this is not a genuine post-sample experiment, as the forecast period is included in the period used for model specification. The one-step ahead value forecasts are generated recursively. Specifically, the forecast of the first observation in the forecast period, $y_{90 \mathrm{q}}$, is derived using parameter estimates obtained using data up to 1989q4. Subsequent forecasts are calculated by re-estimating each model with the new data point and then forecasting the next observation.

Several recent empirical studies have indicated that the forecast performance of nonlinear regime-shift models depends on the regime in which the forecast was made, (see for example, Pesaran and Potter, 1997, Clements and Smith, 1999, and Öcal and Osborn, 1997). In particular, non-linear models have generally shown better forecasting performance during recessions than linear specifications. Further, Dacco and Satchell (1999) show that a nonlinear model with a good in-sample fit may be out-performed when its forecasts are compared using mean square forecast error to a random walk due to the effects of misclassification errors. Thus, evaluating forecast performance in terms of the direction of change for the dependent variable may be more informative about the predictive performance of regime dependent business cycle models than the magnitude of the forecast error captured by the standard forecast accuracy measures such as mean square forecast error (MSFE).

The forecasts here are first evaluated according to two criteria, namely the MSFE and the direction-of-change. The direction of change results reported are the proportion of periods where positive and negative growth are correctly indicated by the model's forecast (Total), along with the corresponding results when periods of positive $(y \geq 0)$ and negative actual $(y<0)$ growth are considered separately. Table 5 provides the results for all models included in Tables 2, 3 and 4. Graphs of the forecasts for some models are shown in Figure 3.

Table 5 indicates that the Hamilton FTP model has a poor forecast performance compared to the univariate AR(1) model over this period, as it not only exhibits a higher MSFE but it correctly predicts the direction of change for just one of the ten observations for which $y<0$, whereas the $\operatorname{AR}(1)$ correctly predicts three such observations. However, the first graph in Figure 3 indicates that both sets of forecasts are poor at predicting the path of actual IOP, especially during the recession. This reinforces the preceding discussion of classification performance, which noted that the FTP model fails to detect any change in regime during the 1990s. 
In terms of the MSFE criterion and considering linear models, the use of single leading indicators (specifically IR, SP, DY, TBY, LR, together with both TS specifications and the level of CBIO) lead to more accurate forecasts compared with the AR(1) model. The direction-of-change forecast results are more complex, with the univariate model being relatively good for the total because it never incorrectly forecasts a decline in IOP. The leading indicator specifications often have a trade-off relative to the $\operatorname{AR}(1)$, with poorer direction-of-change forecasts for periods of actual growth but better forecasts of actual declines. Overall, the level of the CBI optimism balance appears to be the best single indicator linear model in terms of forecast accuracy over this period, with the lowest MSFE and relatively good direction of change results, correctly predicting half of the falls in IOP. Note that the single indicator forecasts using the level of TS, shown in the bottom left-hand panel of Figure 3, forecasts the depth of the recession very successfully.

Nevertheless, we should also bear in mind that the preferred linear specification above was argued to be the three-indicator model with a single lag of DY, CBIO (level) and TBY. It is impressive that Table 5 shows this to also be the most accurate specification in terms of MSFE in this forecasting context. Further, it yields the equal best overall directionof-change score, although it is marginally beaten by the first two-indicator with DY and TBY models for periods of decline alone. The forecasts for the multiple indicator models also appear to capture the depth of the recession as illustrated in Figure 3 (upper right-hand panel) for models of DY with TBY and then combining DY, TBY and the level of CBIO.

In comparison to these linear leading indicator models, the TVTP logistic ones produce disappointing IOP forecasts over this period. This is true even if the comparison is confined to single indicator specifications for the linear case. The TVTP models for IR, SP, HS, DY, TBY and LR have better MSFE values than that of the FTP model, and generally an improvement of the direction-of-change as well. However, these non-linear models are almost always inferior in forecasting according to MSFE compared to the corresponding linear model, and (perhaps more surprisingly) this is often true by direction-of-change too. The use of two indicators in the TVTP framework makes matters worse, with their poor performance in forecasting the recession shown by the lower right-hand graph of Figure 3. In Table 5 and also in Figure 3 (see the illustrative comparison of forecasts using the level of TS), there is little evidence that Markov-switching models perform better in forecasting the 1990s recession for production than linear specifications. 


\section{CONCLUSIONS}

This paper set out to examine the information available from leading indicators in the context of forecasting UK industrial production growth over the business cycle. The results obtained from the selected linear specification, which includes three leading indicators, is promising. This model not only suggests that financial variables (short-term interest rates and the dividend yield of the stock market) can play an important role in forecasting the real economy, but also that business optimism may not fully take account of the information in these variables. At least with the benefit of hindsight, we can conclude that the 1990s recession in UK industrial production could have been foreseen.

Less positive results are, however, obtained about the usefulness of non-linear Markov-switching models in this context. This is surprising in that our companion paper (Simpson et al., 1999) finds these models to outperform linear specifications over a similar period when forecasting UK gross domestic product. Although we can only speculate on the reasons for this, the source could lie in the nature of the 1990s recession for industrial production compared with earlier episodes. In particular, as we have noted above, on the basis of the evidence presented in the two-regime Markov-switching model, it appears to associate one regime with very sharp declines in industrial production, and the 1990s recession never witnessed such a decline in any one quarter. While this is also true to some extent for GDP, the 1990s recession in that case is not as dissimilar to earlier ones as in the case of industrial production. In other words, the root cause could be regime classification errors, which Dacco and Satchell (1999) show can lead to poor forecasts for regime-switching models. Although this suggests a possible explanation, it does not immediately point to how these models should be developed to recognise the recession suffered by UK industrial production during the early 1990s. 
Data Appendix

Table A: Data descriptions with source and sample period

\begin{tabular}{|c|c|c|c|c|}
\hline Variable & Full Name & Sample & Source/ code & $\begin{array}{l}\text { SA or } \\
\text { NSA* }\end{array}$ \\
\hline IOP & $\begin{array}{l}\text { Index of production } \\
\qquad(1990=100)\end{array}$ & $55 q 1-98 q 2$ & ONS/ DVZI & SA \\
\hline \multirow[b]{2}{*}{ IR } & \multirow[b]{2}{*}{$\begin{array}{c}3 \text { month prime bank bills } \\
\text { (period average) }\end{array}$} & $57 q 1-97 q 1$ & ONS/ DKDH & SA \\
\hline & & $97 q 2-98 q 3$ & $\begin{array}{l}\text { Datastream/ } \\
\text { UK3MTHINE }\end{array}$ & SA \\
\hline \multirow[b]{2}{*}{$\mathrm{CBIO}^{* *}$} & \multirow[b]{2}{*}{ CBI Change in Optimism } & $59 q 1-71 q 4$ & ONS/ DKDK & SA \\
\hline & & $72 q 1-98 q 4$ & $\begin{array}{l}\text { Datastream/ } \\
\text { UKCBIOMB }\end{array}$ & NSA \\
\hline HS & Housing Starts & $57 q 1-98 q 1$ & ONS/ CTOZ & SA \\
\hline SP & $\begin{array}{l}\text { FT actuaries all share index } \\
\qquad(10 \text { April } 1962=100)\end{array}$ & $63 q 1-98 q 3$ & ONS/ AJMA & NSA \\
\hline DY & $\begin{array}{c}\text { FT actuaries all share index: } \\
\text { dividend yield } \%\end{array}$ & $63 q 1-98 q 3$ & ONS/ AJMD & NSA \\
\hline TBY & Treasury Bills 3 month yield & $60 q 2-98 q 3$ & ONS/ AJRP & NSA \\
\hline LR & $\begin{array}{c}\text { British Government } \\
\text { Securities: long-dated (20 } \\
\text { years): Par yield - \% per } \\
\text { annum }\end{array}$ & $57 q 1-98 q 3$ & ONS/ AJLX & NSA \\
\hline TS & Term Structure & $60 q 2-98 q 3$ & LR - TBY & NSA \\
\hline M0 & $\begin{array}{l}\text { Notes and coins in } \\
\text { circulation plus sight } \\
\text { deposits }\end{array}$ & $69 q 2-98 q 3$ & ONS/ AVAE & SA \\
\hline
\end{tabular}

* SA = Seasonally Adjusted and NSA = Not Seasonally Adjusted.

** The CBI Industrial Trend Survey was only conducted three times a year between 1959 and 1971 and the ONS have interpolated these values to give a quarterly series before seasonally adjusting it with X-11. After this the author uses a regression with seasonal dummies to seasonally adjust the data. 


\section{ACKNOWLEDGEMENTS}

Financial support from the UK Economic and Social Research Council under grant R000222374 is gratefully acknowledged. We would like to thank seminar participants at the Bank of England and the Stockholm School of Economics for their helpful comments.

\section{REFERENCES}

Akaike H. 1973. Information Theory and an Extension of the Maximum Likelihood Principle. In 2nd International Symposium on Information Theory, Petrov B and Csake F (eds.); Akademiai Kiado: Budapest.

Andreou E, Osborn DR and Sensier M. 1999. A Comparison of the Statistical Properties of Financial Variables in the USA, UK and Germany over the Business Cycle. School of Economic Studies Discussion Paper Series, University of Manchester No.9909. Forthcoming in The Manchester School.

Artis, MJ, Bladen-Hovell RC, Osborn DR, Smith G and Zhang WD. 1995. Turning point prediction for the UK using CSO leading indicators. Oxford Economic Papers 47: 397-417.

Artis MJ, Kontolemis Z and Osborn DR. 1997. Business Cycles for G7 and European Countries. Journal of Business 70: 249-279.

Breusch T. 1978. Testing for Autocorrelation in Dynamic Linear Models. Australian Economic Papers 17:334-355.

Clements MP and Smith JP. 1999. A Monte Carlo Study of the Forecasting Performance of Empirical SETAR Models. Journal of Applied Econometrics 14: 123-141.

Dacco R. and Satchell S. 1999. Why do Regime-switching Models Forecast so Badly? Journal of Forecasting 18: 1-16.

Dow C. 1998. Major Recessions: Britain and the World, 1920-1995. Oxford: Oxford University Press.

Driffill J and Sola M. 1998. Intrinsic Bubbles and Regime Switching. Journal of Monetary Economics 42: 357-373.

Engle RF. 1982. A General Approach to Lagrange Multiplier Model Diagnostics. Journal of Econometrics 20: 83-104.

Filardo AJ. 1994. Business Cycle Phases and Their Transitional Dynamics. Journal of Business and Economic Statistics 12: 299-308. 
Hamilton JD. 1989. A New Approach to the Economic Analysis of Nonstationary Time Series and the Business Cycle. Econometrica 57: 357-384.

Hamilton JD and Perez-Quiros G. 1996. What Do the Leading Indicators Lead? Journal of Business 69: 27-49.

Hess, GD and Iwata S 1997. Measuring and comparing business-cycle features. Journal of Business and Economic Statistics 15: 432-444.

Moore, B 1993. A review of CSO cyclical indicators. Economic Trends no. 477 (July): 99107.

Öcal N and Osborn DR. 1997. Business Cycle Nonlinearities in UK Consumption and Production. School of Economic Studies Discussion Paper Series, University of Manchester No.9701. Forthcoming in Journal of Applied Econometrics.

Osborn DR and Öcal N. 1998. Leading Indicators, Nonlinear Models and Forecasts for UK Macroeconomic Variables. University of Manchester mimeo.

Pesaran MH and Potter SM. 1997. A Floor Ceiling Model of US Output. Journal of Economics Dynamics and Control 21: 661-695.

Ramsey JB. 1974. Classical model selection through specification error tests. In Frontiers in Econometrics, Chapter 1 Zarembka P (ed.); Academic Press: New York.

Ramsey JB. 1996. If nonlinear models cannot forecast, what use are they? Studies in Nonlinear Dynamics and Econometrics 1: 65-86.

Schwartz G. 1978. Estimating the Dimensions of a Model. Annals of Statistics 6: 461-464.

Simpson PW, Osborn DR and Sensier M. 1999. Modelling Business Cycle Movements in the UK Economy. School of Economic Studies Discussion Paper Series, University of Manchester, No. 9908.

Teräsvirta T and Anderson HM. 1992. Characterising Nonlinearities in Business Cycles Using Smooth Transition Autoregressive Models. Journal of Applied Econometrics 7: S119S136.

Tiao GC and Tsay RS. 1994. Some Advances in Non-Linear and Adaptive Modelling in Time Series. Journal of Forecasting 13: 109-131. 
Authors' Biographies:

Paul Simpson has recently completed a $\mathrm{PhD}$ in econometrics at the University of Manchester. He is now working as a Statistician for the Department for Education and Employment in Sheffield.

Denise Osborn is Professor of Econometrics at the University of Manchester. Her primary interests are the time series analysis of macroeconomic time series, with recent work focusing on non-linear business cycle models and the role of financial variables.

Marianne Sensier is a Research Associate at University of Manchester. Research interests include business cycle asymmetries and financial econometrics. 